\title{
Health Insurance and Children in Low- and Middle-income Countries: A Review
}

\author{
SOPHIE MITRA ID \\ Department of Economics, \\ Fordham University, \\ Bronx, NY, USA
}

\author{
MICHAEL PALMER \\ Department of Economics and \\ Finance, RMIT University, \\ Hanoi, Vietnam
}

\author{
SHANNON PULLARO \\ Department of Economics, \\ Fordham University, \\ Bronx, NY, USA
}

\section{DANIEL MONT}

Center for Inclusive Policy, Washington D.C., USA, Leonard Cheshire Disability and Inclusive Development Centre, University College London (UCL), London, UK

\author{
NORA GROCE \\ Leonard Cheshire Disability and Inclusive \\ Development Centre, University College London \\ (UCL), London, UK
}

\begin{abstract}
We conduct the first systematic review of the impact of health insurance on children and their households in low-and middleincome countries where nine-tenths of the world's child population reside. We find only 13 studies for seven countries published between 2000 and 2014 which assess the insurance impacts for children, controlling for self-selection and heterogeneity. Nine out of 10 studies reviewed provide consistent evidence that health insurance provides financial protection. The results are more mixed for health utilisation and health outcomes. Policy-makers would benefit from additional research on whether and how health insurance benefits children.
\end{abstract}

\section{Introduction}

This review centres on the effects of health insurance programs in low- and middle-income countries (LMICs) on the health and health-care outcomes for children. The health of children is widely understood as an inherently important component of their wellbeing and instrumental in promoting their productivity as adults (Behrman \& Rosenzweig, 2004). Populations in many parts of the world are young, especially in LMICs. For instance, in Africa, children under age 15 account for 41 per cent of the population (United Nations, 2015). The health of children is therefore central to global human, economic and social development. This was reflected in the explicit

JEL classifications: I13, J13, J15

Correspondence: Sophie Mitra, Fordham University Rose Hill Campus, 441 Fordham Road, Dealy E524, Bronx, NY 10458-9993, USA. Email: mitra@fordham.edu identification of child health as a key component of the Millennium Development Goals (MDGs) and in the more recent Sustainable Development Goals (SDGs; United Nations Development Programme, 2016).

Significant advancements have been achieved. The rate of mortality for children under the age of 5 worldwide almost halved over the period 19902013 (Sepulveda \& Murray, 2014; Wang et al., 2014). However, the reduction fell short of the targeted two-thirds in the MDGs. Progress on maternal health has been less impressive, with only one-third of the targeted reduction rate in maternal mortality rate achieved ( 26 per cent, compared to 75 per cent). Diseases remain a substantial cause of preventable child deaths. In 2013, malaria, lower respiratory infections and diarrhoea collectively accounted for approximately one-third of childhood deaths. Child health therefore continues to be a cornerstone in the new SDGs (United Nations Development Programme, 2016).

(C) 2017 The Authors. Economic Record published by Wiley Publishing Asia Pty Ltd on behalf of Economic Society of Australia.

This is an open access article under the terms of the Creative Commons Attribution License, which permits use, distribution and reproduction in any medium, provided the original work is properly cited. 
As a way to improve health and equity in access to health services for children as well as adults, many LMICs are moving towards universal health coverage (UHC), defined by the World Health Organization (WHO) as 'all people receiving quality health services that meet their needs without being exposed to financial hardship in paying for the services' (WHO, 2014). While UHC is currently very high on the global health agenda, the road to achieving it is far from straightforward. Currently little consensus exists on how LMICs should structure their reforms to move towards UHC (Lagomarsino et al., 2012). There are multiple ways to increase the funds available to health care, including taxation, health insurance, out-ofpocket payments and innovative mechanisms such as external donor assistance (WHO, 2010). In reality, countries employ a mix of these strategies. It is generally agreed that out-of-pocket payments are a regressive form of health financing with harmful consequences for the poor. WHO (2010) makes strong policy recommendations to reduce direct payments for health care through risk pooling and prepayment for people who can afford to pay, either through taxation and/or insurance contributions (WHO, 2010).

Health insurance has become an important mechanism through which many LMICs are committing to UHC. Systems typically comprise a collection of contributory and non-contributory schemes targeted to a range of population groups. Most systems include all or a combination of the following: a compulsory contributory scheme for civil servants and formal sector employees; a non-contributory scheme for social beneficiary groups such as the poor and persons with disabilities; and a voluntary contributory scheme for informal sector workers and anyone else willing to pay a private premium. In theory, through the collection of premiums from the non-poor, the system is able to subsidise premiums for the poor or nearpoor. However in practice, premiums collected from the formal sector in LMICs are insufficient and states commonly subsidise the premiums of voluntary schemes. Yet the take-up is often low, as demonstrated by the case of Vietnam where approximately 40 per cent of the population remains uninsured, the majority of whom are people working in the informal sector. ${ }^{1}$ Thailand represents a unique case where since 2001, premiums for the informal sector have been paid fully out of the state budget with enrollees

\footnotetext{
${ }^{1}$ Calculation by authors using the Vietnam Household Living Standards Survey 2010.
}

subject to a 30 baht co-payment, making it the first LMIC to achieve UHC. In most instances, schemes are publicly provided. India presents an exception, with significant efforts being made to expand the private insurance system alongside state governmentsponsored health insurance schemes (La Forgia \& Nagpal, 2012). ${ }^{2}$ Schemes may be provided at the national or community level, with the former seemingly most common.

Children can be covered under any of the contributory or non-contributory schemes outlined above. There are schemes that specifically target children and schemes for the general population under which children may become eligible, such as non-contributory schemes for the poor or as dependants of compulsory contributory schemes. Many countries have expanded health insurance coverage to school-aged children through targeted non-contributory programs. For instance, in 1992, Egypt introduced its School Health Insurance Programme, which provided free health insurance to children of primary school age (Yip \& Berman, 2001). The Philippines expanded insurance coverage among school-age children seeking care in 30 randomly selected treatment sites (Quimbo et al., 2011). In Vietnam, by contrast, school-aged children were included among 'voluntary' insurance target groups yet were strongly encouraged by schools to pay the state-subsidised private premium. Later, in 2005, preschool-aged ( $<6$ years) children in Vietnam became eligible for non-contributory health insurance. It is also common for children to be included in non-contributory health insurance programs targeted to mothers and their children. For example, Colombia created its Contributive and Subsidised Regimes of insurance coverage during the 1990 s, which provided generous benefits to mothers and their newborns (Camacho \& Conover, 2013). Bolivia established its National Maternal and Child Insurance before expanding it into a national public health insurance program. Similarly, Malawi introduced maternal and newborn health insurance in 2004 in response to the MDGs (Brenner et al., 2014).

Several reviews of the impact of health insurance exist, but none specific to children (e.g. Giedion \& Díaz, 2010; Spaan et al., 2012). There is a clear need for a review of the impact of health

\footnotetext{
${ }^{2}$ By 2010, 19 per cent of the population was covered by the government-sponsored schemes while another 25 per cent held private insurance.
} 
insurance programs on children, given the central role of the health of children to human development, and because a number of countries have implemented reforms to expand health insurance coverage through programs targeted at children (e.g. Vietnam). The demand for health care for children may have a different price elasticity than that for adults (Leibowitz et al., 1985; Sauerborn et al., 1994; Ching, 1995), which may lead to different effects for children than for adults. To our knowledge, this article is the first systematic and comprehensive examination of the effect of health insurance on utilisation, financial protection and health outcomes for children in LMICs. It aims to inform future research and interventions related to UHC in general, and for children in particular. We limit our review to studies that apply rigorous impact evaluation methods as those that best inform evidence-based policy. Studies were identified based upon an extensive search of bibliographic databases covering published articles in health services research, medical and social sciences journals. We provide a theoretical and empirical background for the study, then organise and synthesise results before discussing the findings and their implications for future research.

\section{Background}

\section{(i) Expected Impact of Health Insurance}

According to economic theory, health insurance coverage is expected to lead to greater health-care utilisation by reducing the cost of care (Phelps, 1997). In turn, health insurance is expected to improve health. The effect on total out-of-pocket health expenditures, however, is less clear due to the offsetting effect of an increased number of visits. If the price elasticity of demand for health care is less than 1, then health insurance should reduce out-of-pocket health expenditures for the individual.

If all household members are covered by health insurance, then health insurance should reduce out-of-pocket health expenditures for the family. If only some household members are eligible for health insurance, there might be an offsetting effect across members. For instance, household out-of-pocket expenditures may stay the same, while increasing for those without insurance and decreasing for those with insurance. Finally, with respect to health status, to the extent that health insurance improves access to quality services, health insurance is expected to improve health.
The analysis of the expected impact of health insurance on health-care utilisation is complex as one looks into the type of service, supply-side considerations and the broader context of health systems in LMICs. One expects an increase in outpatient visits, whether for preventive care or acute care. For children, this is especially the case for preventive care, with, for instance, an expected increase in immunisations. The expected effect is less clear for inpatient visits due to increased preventative and primary health-care usage. Buchmueller et al. (2005) claim that a lack of insurance may cause inefficient use of medical care and avoidable hospitalisations (inadequate prevention and excessive reliance on inpatient care). Expanding health insurance coverage may thus lead to reductions in some types of hospital utilisation.

The nature of the effect on the utilisation of different types of services is also affected by the characteristics of the health insurance program (benefits, co-payments) and supply-side considerations, which are not homogeneous across programs and countries. Extending coverage to the uninsured may impact the aggregate demand for health-care services. Health-care providers may consequently adjust to changes in demand. Given capacity constraints, providers may adjust their services to respond to the demand from the newly insured, which may change the nature of public services provided, that is, towards those who would typically be covered by health insurance program expansions. In turn, this might lead to a reduction in the quality of public services provided and to a subsequent switch to the utilisation of private services.

Finally, factors specific to the LMIC context may influence the impact of health insurance, including a lack of awareness of or trust in public programs and a lack of access to health-care infrastructure (e.g. Svoronos et al., 2014).

\section{(ii) Identification Issues}

Identifying the effects of health insurance is very challenging. A simple comparison of means for the insured and the uninsured using observational data does not help, since health insurance coverage is not random, but rather the outcome of demand and supply factors, some of which are a function of health status and individual or household preferences. A simple comparison would give biased estimates: it would reflect the causal effect of health insurance combined with the effect of unmeasured characteristics that are correlated with health insurance coverage. The direction of the bias due to unobserved heterogeneity is unclear. It could be positive due to 
adverse selection. Children in worse health are more likely to demand health insurance, but also to demand more health care. The bias could be negative when health insurance programs are made available to children who are likely to be healthier, such as children enrolled in school. An additional challenge is that health insurance expansions could be part of broader health sector reforms that simultaneously affect the supply and demand side of health care, which makes it difficult to isolate the effect of health insurance.

The best-known, and only long-term, experimental study on the impact of health insurance on care utilisation and health outcomes is the RAND Health Insurance Experiment conducted in the USA in the 1970s and 1980s, which found that participants who received free care used more health care than those who paid a co-payment (Manning et al., 1987). The study showed little difference in the health outcomes of participants who received free care compared to those who paid a share of their health care. It is noted that the study did not evaluate the impact of having insurance per se but rather randomised individuals by level of co-payment.

\section{Methodology}

\section{(i) Inclusion Criteria}

This review included evaluation studies that had the following characteristics:

1 Studies assessed the impact of health insurance on at least one quantifiable outcome for children and/or households.

2 Studies were conducted in LMICs as per the World Bank country classification.

3 Studies were published or made available since 2000. This criterion was used to include studies with recent or current relevant policy contexts.

4 Studies covered universal health insurance programs (for the entire population) and health insurance programs targeted at children. Health insurance programs targeted at pregnant mothers are beyond the scope of the study. ${ }^{3}$

\footnotetext{
${ }^{3}$ However, in studies of universal health insurance programs, and in studies of programmes targeted at children in settings that also have maternal programmes, the measured impact of health insurance on children may include, to some extent, the impact on children of providing health insurance to pregnant mothers.
}

5 This literature review is limited to studies that use a rigorous econometric analysis that attempts to address the endogeneity of health insurance. This can be done when subjects are randomly assigned to different health insurance coverage as in the case of the RAND experiment mentioned above. Besides randomised controlled trials, most commonly used methods mainly include the following: difference-in-difference estimation, propensity score matching, regression discontinuity, instrumental variable methods, or a mix of these methods (Khandker et al., 2010). Using one of the methods above was not necessarily considered enough for a study to be included: three of the authors read and assessed the quality of the evaluation design for all screened papers.

\section{(ii) Search Strategy}

Relevant reports and papers, both published and unpublished, were identified according to the following steps:

1 Electronic databases. We conducted several database searches. We started with three databases where relevant quantitative impact evaluations were expected to be found: EconLit, the Impact Evaluation Repository of the International Initiave for Impact Evaluation (3ie), and PubMed. In addition, as a check, we performed a cross-database search using the EBSCO Discovery Service (OneSearch) that covered the following databases: Medline, SocIndex, Science Direct, JSTOR journals, PsycInfo and SocWork Abstracts.

2 Citation chasing. The reference list of every included paper was checked to identify any possible additional studies.

3 Internet searches. Finally, we used the advanced search options in Google and Google Scholar for a search of the World Wide Web.

In each database, we used combinations of keywords that dealt with: (i) relevance to the research question (health insurance, health coverage, children); (ii) relevance to the LMIC context (LMIC, developing country); (iii) outcomes such as health-care utilisation, health expenditures, and health outcomes (e.g. stunting, child wasting); and (iv) econometric analysis (impact evaluation). The search was restricted to English-language studies.

\section{(iii) Screening}

Several database searches led to several thousand citations in total. Many citations could 
easily be excluded given the lack of relevance based on the title. If the study was included based on the title, the abstract was then reviewed. If the study was included based on the abstract, the full text of the article was retrieved and checked against the inclusion criteria above. We report below on our main database searches. Other searches (within the same database using different terms, or in different databases) did not lead to any additional results.

The EconLit search with 'health insurance' and 'children' as search terms connected with the Boolean operator (AND) yielded 246 papers, of which we included seven published or working papers.

The 3ie repository, using 'health insurance' as a search term, led to 69 results, of which we included six papers (two of these six papers had already been found in EconLit).

The PubMed database (using 'health insurance', 'children' and 'developing countries') led to 211 papers: we excluded all but two studies, both of which had already been found in the EconLit and 3ie searches.

We checked the results of the above searches with a cross-database search using the EBSCO Discovery Service for the cross-database search. This search yielded 838 records, none of which were in addition to those that had been previously identified through the search of EconLit, Pub Med and the 3 ie repository.

Finally, through citation chasing and internet searches, we identified two more papers, leading to a total of 13 papers.

It should be noted that we do not aggregate the outcomes of the studies into a meta-analysis. Many of the outcome measures and estimation strategies that we found were not comparable across studies, and the insurance programs were different across countries. It would thus be misleading to aggregate their results.

\section{Results}

In total, the review led to 13 papers that cover health insurance expansion programs in seven countries: Burkina Faso, Colombia, China, the Philippines, Rwanda, Thailand and Vietnam. The characteristics of each of these programs are presented in Appendix Table A1. An overview of these articles is given in Table 1 and each of them is synthesised in Table 2. Results in Tables 2-4 are first listed for programs targeted at children and then for other programs. Seven out of 13 papers are concerned with health insurance
TABLE 1

Overview of 13 Studies in the Review

\begin{tabular}{lc}
\hline & $\begin{array}{c}\text { Number of } \\
\text { studies }\end{array}$ \\
\hline Scope of insurance programs* & 5 \\
Programs targeted at children & 9 \\
Other programs & \\
Methodology & 3 \\
Difference-in-difference (DID) & 1 \\
Propensity score matching (PSM) & 4 \\
DID and PSM combined & 3 \\
Randomised controlled trial & 2 \\
Regression discontinuity design & \\
Relevant outcomes & 10 \\
Service utilisation & 9 \\
Financial protection & 10 \\
Health outcomes & \\
\hline
\end{tabular}

Note: * One study (Guindon, 2014) covers a program targeted at children and another program that is not targeted, hence the number of studies here sums to 14 .

expansion for the general population in Burkina Faso (Fink et al., 2013), China (Wagstaff \& Yu, 2007; Chen \& Jin, 2012), Colombia (Giedion \& Uribe, 2009; Miller et al., 2013), Rwanda (Lu et al., 2012), and Thailand (Gruber et al., 2014). Five papers cover health insurance programs targeted at children in the Philippines (Kraft et al., 2009; Quimbo et al., 2011) and Vietnam (Wagstaff \& Pradhan, 2005; Nguyen \& Wang, 2013; Guindon, 2014; Palmer et al., 2015). It should be noted that one paper (Guindon, 2014) deals with both a program targeted at children and a program for a larger population. ${ }^{4}$

With respect to methodology, three articles used a difference-in-difference design (Nguyen \& Wang, 2013; Gruber et al., 2014; Guindon, 2014), one paper used propensity score matching (Lu et al., 2012), four papers used difference-indifference and propensity score matching combined (Wagstaff \& Pradhan, 2005; Wagstaff \& Yu, 2007; Giedion \& Uribe, 2009; Chen \& Jin, 2012), three papers used a randomised controlled trial (Kraft et al., 2009; Quimbo et al., 2011; Fink et al., 2013), and two papers used a regression discontinuity design (Miller et al., 2013; Palmer et al., 2015).

\footnotetext{
${ }^{4}$ Its characteristics and results are listed for the two programs separately in Tables $2-4$.
} 


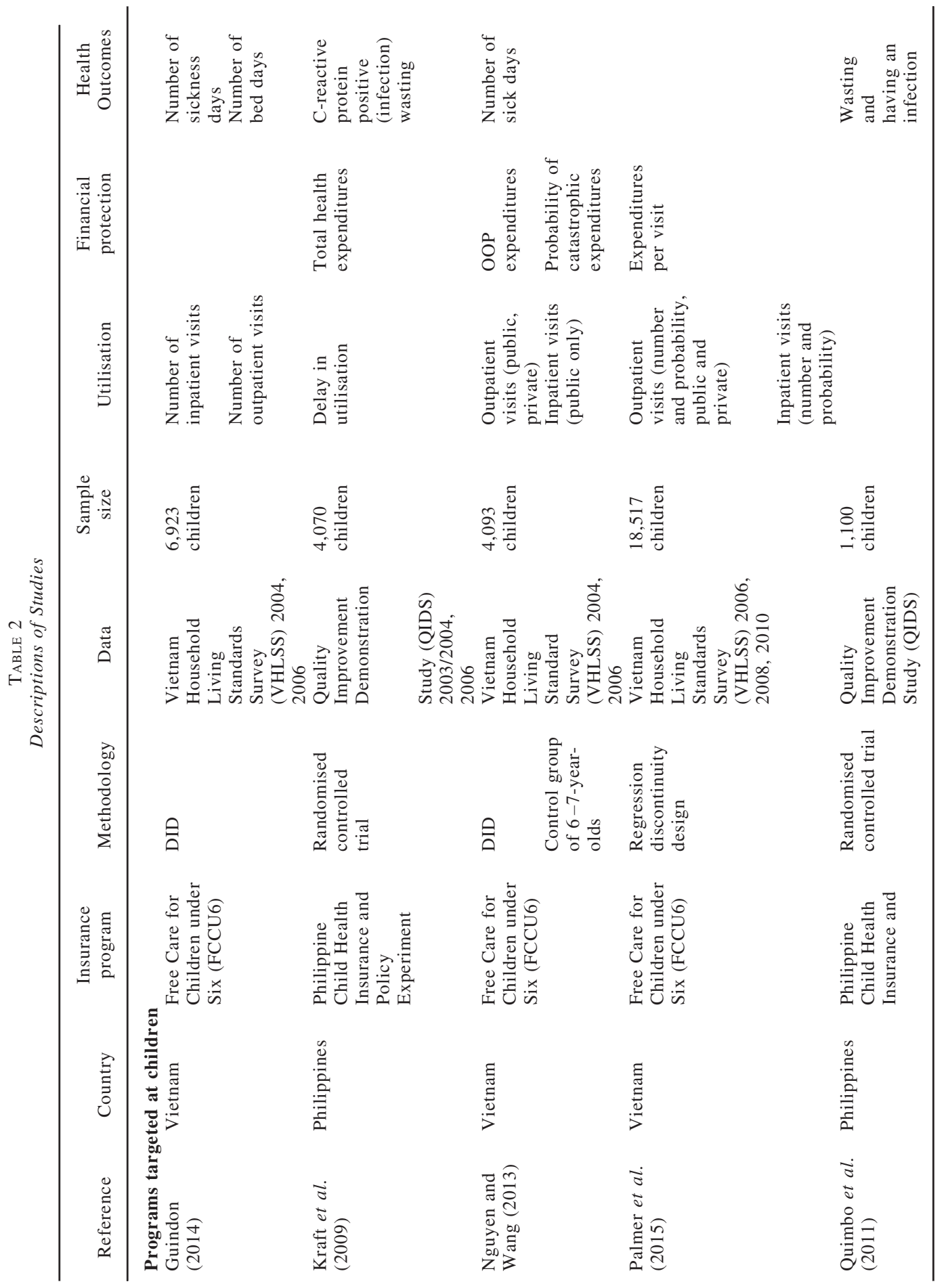




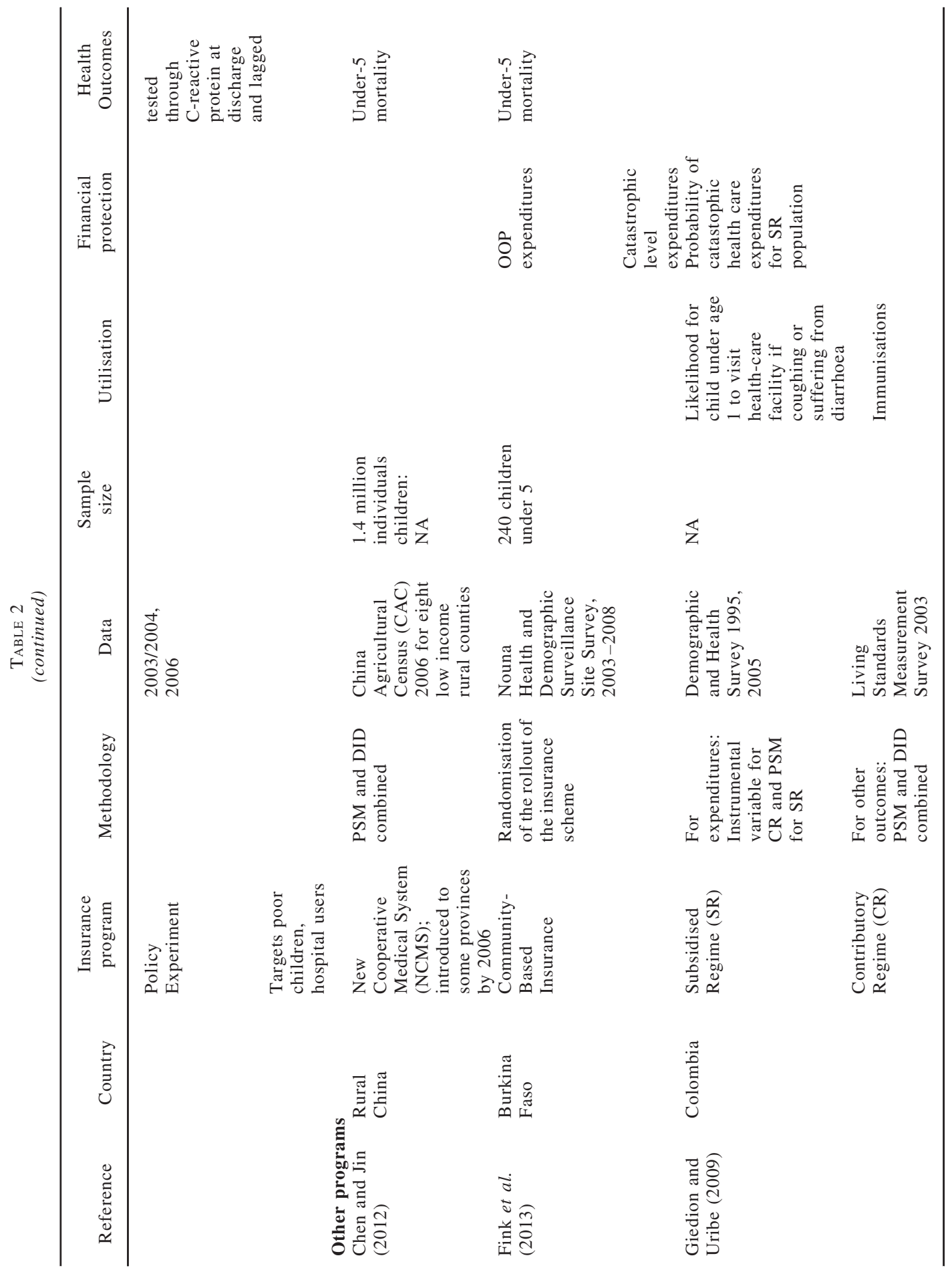

(C) 2017 The Authors. Economic Record published by Wiley Publishing Asia Pty Ltd on behalf of Economic Society of Australia. 


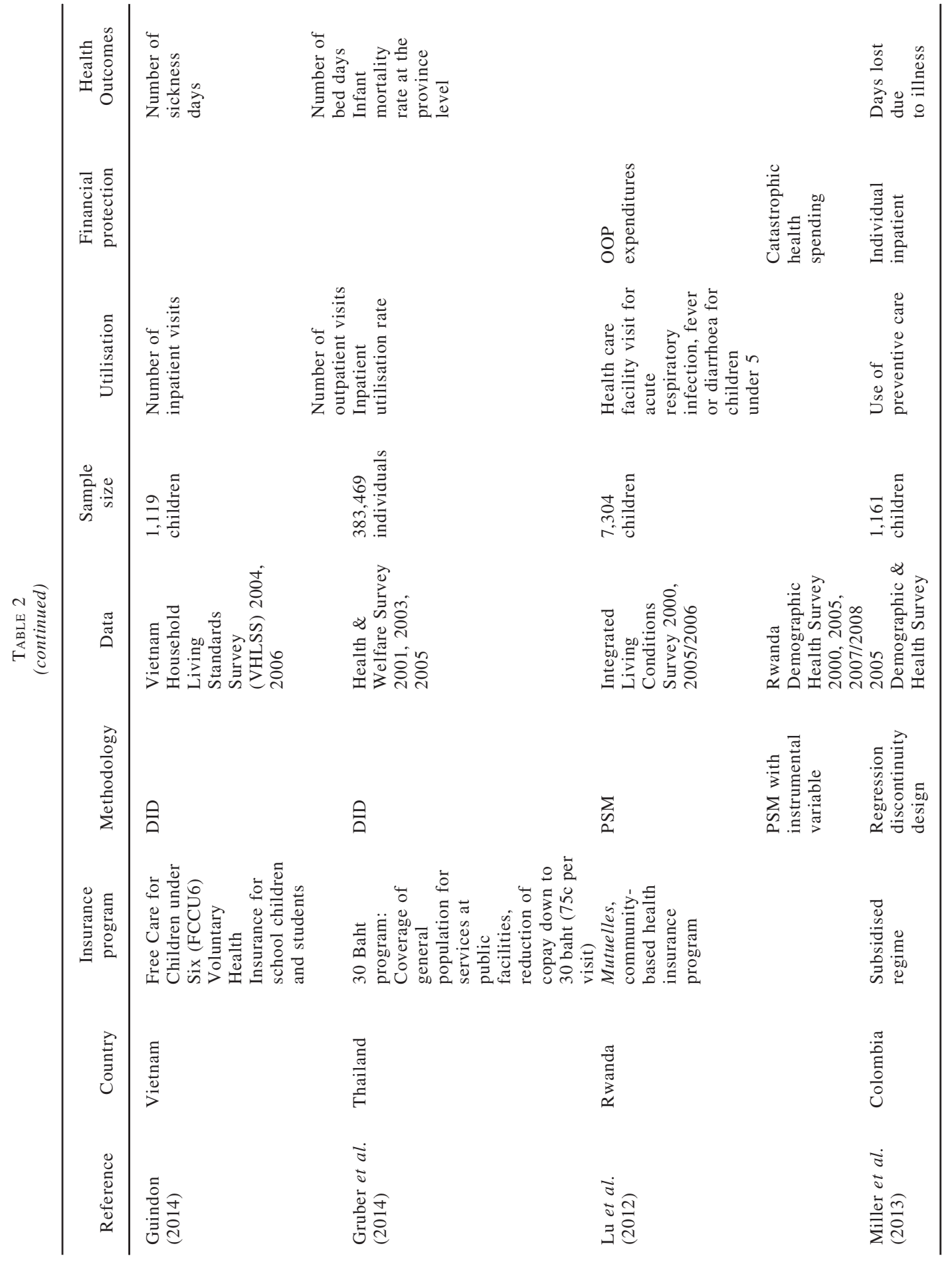




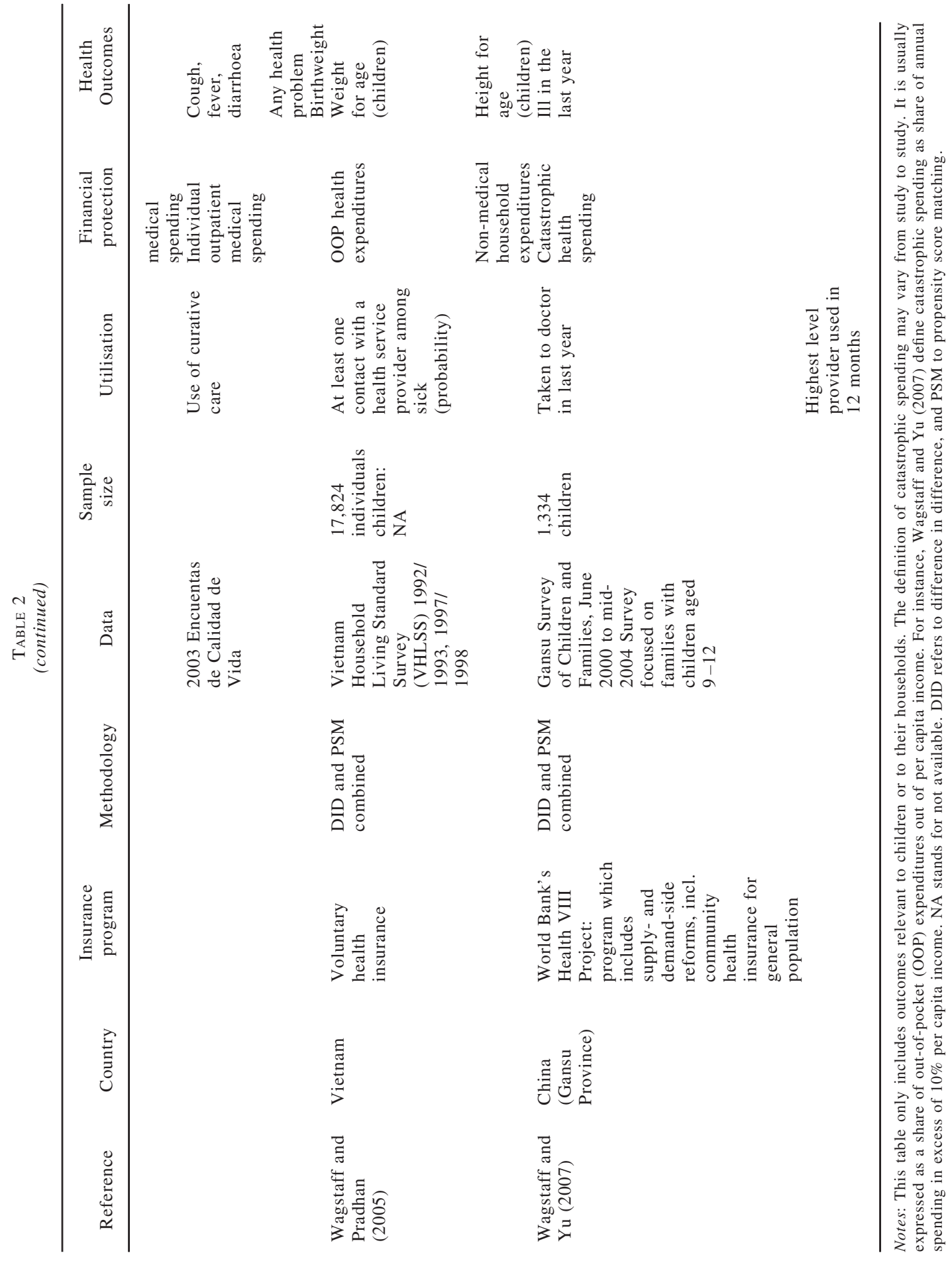

(C) 2017 The Authors. Economic Record published by Wiley Publishing Asia Pty Ltd on behalf of Economic Society of Australia. 
The studies use a variety of outcomes: ten studies have service utilisation outcomes, nine have financial protection outcomes, and ten have health outcomes. It should be noted that in these studies, utilisation and health outcomes are measured at the child level, while financial protection is typically measured at the household level. Only three studies pay attention to subgroups of children or their households: Giedion and Uribe (2009) among urban, rural, poorest and poor quintiles; Wagstaff and Pradhan (2005) and Wagstaff and $\mathrm{Yu}$ (2007) by income quintile.

\section{(i) Effects on Service Utilisation}

Ten studies assessed the impact of health insurance on health-care utilisation in six countries. Their main results are presented in Table 3. Broadly, health-care utilisation refers to individuals seeking care for ailments, injuries or preventive care. Services may include well care visits, sick and emergency outpatient care, and inpatient care (hospital admissions). Several papers use broad health-care utilisation outcome measures, such as any contact with a service provider (Wagstaff \& Pradhan, 2005) while other papers use specific service utilisation indicators such as visits to health-care providers among children under 5 with acute respiratory infections, diarrhoea or fever (Lu et al., 2012).

Six of these ten studies find positive effects of health insurance on care utilisation for children (Giedion \& Uribe, 2009; Kraft et al., 2009; Lu et al., 2012; Miller et al., 2013; Gruber et al., 2014; Palmer et al., 2015). For instance, for Colombia, Giedion and Uribe (2009) find that the likelihood that a child gets immunised and that a child with a cough visits a health-care facility were 6.1 per cent and 10.7 per cent greater respectively for those under the insurance program (Giedion \& Uribe, 2009). For Thailand, Gruber et al. (2014) show that the '30 Baht' program led to a 12 per cent increase in inpatient health service utilisation for the overall population during its first 4 years. For infants $(0-1$ years of age) and women of child-bearing age service utilisation grew 2.5 times faster. In the Philippines, Kraft et al. (2009) find that delays in seeking care were 5.3 per cent lower in health insurance intervention sites than compared to control sites.

The other four studies have mixed results, depending on the age group of children, the type of services (e.g. inpatient versus outpatient), the unit of analysis or the evaluation methodology.
Wagstaff and $\mathrm{Yu}$ (2007) have mixed results on the impact of the World Bank's Health VIII project in Gansu province, China, on the use of health services. For instance, it leads to an increase in hepatitis B immunisation at the county level, but has a negative impact on immunisations overall at the village level (this latter result is sensitive to the econometric specification). For the case of Vietnam, Wagstaff and Pradhan (2005) find for the Voluntary Health Insurance program that the probability of contact with a health-care provider for a sick person increases for children 5 and over, but not for children under 5. Guindon (2014) finds that Vietnam's health insurance program for children under 6 increases outpatient visits by 17 per cent but has no significant effect on inpatient admissions, while Nguyen and Wang (2013) find for the very same program a significant increase in inpatient care but no significant change in outpatient care. Both Guindon (2014) and Nguyen and Wang (2013) use difference-indifference estimation strategies and the Vietnam Household Living Standard Survey. However, they use different control groups, which may explain the difference in results. Using an alternative regression discontinuity design, Palmer et al. (2015) find a positive utilisation impact for both inpatient and outpatient services. Consistent with Guindon (2014), the authors find a larger impact on outpatient service utilisation.

\section{(ii) Effects on Financial Protection}

We reviewed ten studies that analysed the effects of health insurance on financial protection. Financial protection is measured through catastrophic health spending and/or out-of-pocket health expenditures, and the variability of medical spending (Table 3). Catastrophic spending is understood as a level of health-care expenditures that exceeds a given threshold of income, which is typically proxied by consumption expenditures as a more permanent measure of income in LMICs settings. Thresholds and consumption expenditure types vary from study to study. For instance, Wagstaff and $\mathrm{Yu}$ (2007) define it as spending exceeding 10 per cent of total consumption expenditures, which is the most commonly used threshold when total expenditure is used as the denominator. In addition, one has to bear in mind that financial protection is usually measured at the household level. In the case of householdlevel outcomes, for insurance programs targeted at children, a lack of change in expenditures, for instance, could be due to a redistribution of 
TABLE 3

Main Results on Utilisation and Expenditures

\begin{tabular}{|c|c|}
\hline Reference & Results \\
\hline \multicolumn{2}{|c|}{ Programs targeted at children } \\
\hline \multirow[t]{2}{*}{ Guindon (2014) } & Increase in outpatient visits by $17 \%$ for children under 6 \\
\hline & No significant effect found on inpatient admissions for children under 6 \\
\hline Kraft et al. (2009) & $\begin{array}{l}\text { Delays in seeking care were } 5.29 \% \text { lower in the intervention sites (insurance) than in the } \\
\text { control sites }\end{array}$ \\
\hline \multirow{3}{*}{$\begin{array}{l}\text { Nguyen and Wang } \\
\text { (2013) }\end{array}$} & An increase in total utilisation (private and public), but not statistically significant \\
\hline & $\begin{array}{l}\text { Increase in inpatient admissions in public hospitals. No consistent effect was found on } \\
\text { the number of outpatient contact in the public sector, nor in the private sector }\end{array}$ \\
\hline & $\begin{array}{l}\text { OOP spending and the probability of catastrophic spending was significantly reduced in } \\
\text { one of two models }\end{array}$ \\
\hline \multirow[t]{3}{*}{$\begin{array}{l}\text { Palmer et al. } \\
\quad(2015)\end{array}$} & $\begin{array}{l}\text { Insurance for children under } 6 \text { increases the probability of an inpatient visit }(+6.8 \%) \text { and } \\
\text { an outpatient visit }(+21.7 \%)\end{array}$ \\
\hline & Insurance increases the average number of inpatient $(+1.13)$ and outpatient visits $(+0.75)$ \\
\hline & No significant impact with respect to OOP expenditures \\
\hline \multicolumn{2}{|l|}{ Other programs } \\
\hline Fink et al. (2013) & $\begin{array}{l}\text { Insurance had negative but small effect on average OOP expenditures in the target areas, } \\
\text { but reduced by } 30 \% \text { the likelihood of catastrophic health expenditure }\end{array}$ \\
\hline \multirow[t]{2}{*}{$\begin{array}{l}\text { Giedion and Uribe } \\
\text { (2009) }\end{array}$} & $\begin{array}{l}\text { Insurance improved access and utilisation for both the SR and the CR programs (e.g. } \\
\text { child taken to health care facility when coughing }(+10.7 \%) \text { or having diarrhoea }(+7.4 \%) \text {, } \\
\text { child immunisation complete }(+6.1 \%))\end{array}$ \\
\hline & $\begin{array}{l}\text { Insurance has reduced the incidence of catastrophic health spending, especially among } \\
\text { more disadvantaged groups (those in rural areas, poorest and self-employed) }\end{array}$ \\
\hline Guindon (2014) & $\begin{array}{l}\text { Twofold increase in inpatient admissions for school-age children and students, but no } \\
\text { effect found on outpatient visits }\end{array}$ \\
\hline \multirow{3}{*}{$\begin{array}{l}\text { Gruber et al. } \\
\text { (2014) }\end{array}$} & Increase by $12 \%$ for the general population of the overall inpatient utilisation rate \\
\hline & Increase in overall utilisation rate is 2.5 times bigger for women and infants \\
\hline & Substitution of public for private care for general population \\
\hline \multirow[t]{2}{*}{ Lu et al. (2012) } & $\begin{array}{l}\text { Visits to health-care facilities for under-5 children with acute respiratory infection, } \\
\text { diarrhoea, or fever increased two- to threefold due to insurance }\end{array}$ \\
\hline & $\begin{array}{l}\text { Reduction in OOP expenditures and in the probability of catastrophic health-care } \\
\text { spending for overall population with health insurance }\end{array}$ \\
\hline \multirow[t]{3}{*}{ Miller et al. (2013) } & $\begin{array}{l}\text { SR eligibility is associated with reductions in the variability* of inpatient medical } \\
\text { spending }\end{array}$ \\
\hline & $\begin{array}{l}\text { Significant increase in use of preventive care (preventive physician visit and number of } \\
\text { growth development checks last year) }\end{array}$ \\
\hline & No change found for curative medical care among children \\
\hline \multirow[t]{3}{*}{$\begin{array}{l}\text { Wagstaff and } \\
\text { Pradhan (2005) }\end{array}$} & $\begin{array}{l}\text { The probability of contact with a health-care provider for a sick person increased for } \\
\text { children } 5 \text { and over }(+3.9 \%) \text {, but not for children under } 5\end{array}$ \\
\hline & Some reduction in OOP expenditures \\
\hline & Increase in non-medical expenditures, by more than reduced OOP \\
\hline \multirow[t]{2}{*}{$\begin{array}{l}\text { Wagstaff and Yu } \\
\text { (2007) }\end{array}$} & $\begin{array}{l}\text { Little impact is found on the use of services (for instance, Increase in hepatitis B and } \\
\text { polio immunisation at the county level, but negative impact on overall immunisations at } \\
\text { the village level (although this result holds only for one specification) }\end{array}$ \\
\hline & $\begin{array}{l}\text { Reduced OOP spending, and the incidence of catastrophic spending and impoverishment } \\
\text { through health expenses }\end{array}$ \\
\hline
\end{tabular}

Note: *Variability is defined as the difference between individual spending and county mean spending.

expenditures towards uninsured individuals in the household. Results thus need to be interpreted with caution.

The five papers that use catastrophic spending as a financial protection indicator find that health insurance reduces the likelihood of catastrophic spending (Wagstaff \& Yu, 2007; Giedion \& Uribe, 2009; Lu et al., 2012; Fink et al., 2013; Nguyen \& Wang, 2013). Out of the six papers that use out-of-pocket health expenditures as an 
TABLE 4

Main Results on Health Outcomes

\begin{tabular}{|c|c|}
\hline Reference & Results \\
\hline \multicolumn{2}{|c|}{ Programs targeted at children } \\
\hline Kraft et al. (2009) & $\begin{array}{l}\text { Authors infer that insurance may have positive effects on health outcomes and } \\
\text { expenditures given that health insurance reduces delays }\end{array}$ \\
\hline $\begin{array}{l}\text { Nguyen and Wang } \\
(2013)\end{array}$ & $\begin{array}{l}\text { Number of sick days was reduced (statistically significant only at } 10 \% \text { ) in one of two } \\
\text { models }\end{array}$ \\
\hline \multirow{2}{*}{$\begin{array}{l}\text { Quimbo et al. } \\
\text { (2011) }\end{array}$} & At discharge: no effect on C-reactive protein (CRP) \\
\hline & $\begin{array}{l}\text { Post-discharge ( } 4-10 \text { weeks later): intervention reduces probability of testing CRP } \\
\text { positive by } 4-9 \text { percentage points and of wasting by } 9-12 \text { percentage points }\end{array}$ \\
\hline \multicolumn{2}{|r|}{ 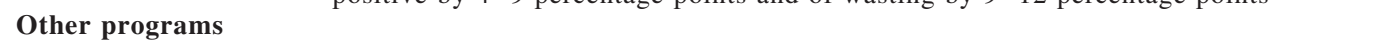 } \\
\hline $\begin{array}{l}\text { Chen and Jin } \\
(2012)\end{array}$ & $\begin{array}{l}\text { Effect found on child mortality and school enrolment with raw data or PSM model. } \\
\text { However, after controlling for selection bias by combining } \\
\text { DID and PSM, the New Cooperative Medical System (NCMS) has no effect on under-5 } \\
\text { mortality }\end{array}$ \\
\hline Fink et al. (2013) & No significant effect on under-5 mortality was found \\
\hline Guindon (2014) & $\begin{array}{l}\text { No signicant effect of voluntary health insurance program found on number of sick or bed } \\
\text { days for students }\end{array}$ \\
\hline $\begin{array}{l}\text { Gruber et al. } \\
\text { (2014) }\end{array}$ & $\begin{array}{l}\text { Reduction in infant mortality: a } 10 \% \text { increase in the fraction enrolled in the program } \\
\text { reduced infant mortality by } 0.65 \text { per } 1,000 \text { births }\end{array}$ \\
\hline \multirow[t]{2}{*}{ Miller et al. (2013) } & $\begin{array}{l}\text { SR enrolment is associated with } 1.4 \text { fewer child days absent from usual activities due to } \\
\text { illness in the past month }\end{array}$ \\
\hline & $\begin{array}{l}18 \text { percentage point reduction in the self-reported incidence of cough, fever or diarrhoea } \\
\text { among children, but not statistically significant }\end{array}$ \\
\hline $\begin{array}{l}\text { Wagstaff and } \\
\text { Pradhan }(2005)\end{array}$ & $\begin{array}{l}\text { Children under } 5 \text { increased height- and weight-for-age by } 2.35 \mathrm{~cm}(2 \%) \text { and } 0.75 \mathrm{~kg} \\
(4 \%) \text {, respectively. No significant effect found for older children }\end{array}$ \\
\hline Wagstaff and Yu & Reduction of illness among children* \\
\hline
\end{tabular}

Note: ${ }^{*}$ This result for children is presented in the working paper of Wagstaff and Yu (2007) and is consistent with a similar effect for the entire population given in the published version.

indicator of financial protection, five find that health insurance has a negative and significant effect (Wagstaff \& Pradhan, 2005; Wagstaff \& Yu, 2007; Lu et al., 2012; Fink et al., 2013; Nguyen \& Wang, 2013). Only Palmer et al. (2015) does not find evidence of a significant effect on out-of-pocket health expenditures for Vietnam's health insurance program for children under age 6 . This result is consistent with the result of the Nguyen and Wang (2013) study of the same program for children aged $0-3$, but different from the negative and significant impact on expenditures they find for children aged 4-5. This difference in results for children aged 4-5 could come from the difference in sample and methodology: Nguyen and Wang (2013) use a sample of non-poor children only with two waves of the Vietnam Household Living Standard
Survey (2004 and 2006) and with a differencein-difference estimation, while Palmer et al.'s (2015) estimates are for all children near the age cut-off of 6 using regression discontinuity and based on 2006, 2008 and 2010 Vietnam Household Living Standard Survey data.

Finally, Miller et al. (2013) find that insurance in Colombia is associated with reductions in the variability of inpatient medical spending, where variability is defined in terms of the difference between the individual medical spending and the county mean medical spending.

\section{(iii) Effects on Health Outcomes}

Ten of the 13 studies we examined assessed the impact of health insurance on health outcomes in LMICs. Their main results are presented in Table 4. Among the health outcomes were 
mortality (Chen \& Jin, 2012; Fink et al., 2013; Gruber et al., 2014), morbidity (Wagstaff \& Yu, 2007; Quimbo et al., 2011; Miller et al., 2013; Nguyen \& Wang, 2013; Guindon, 2014), anthropometric outcomes (Wagstaff \& Pradhan, 2005; Kraft et al., 2009; Quimbo et al., 2011) and broad activity limitation (Miller et al., 2013).

Four of the ten studies find that health insurance leads to health improvements (Wagstaff \& Yu, 2007; Kraft et al., 2009; Nguyen \& Wang, 2013; Gruber et al., 2014). For instance, Gruber et al. (2014) find a reduction in infant mortality: a 10 per cent increase in the fraction enrolled in the program reduced infant mortality by 0.65 per 1,000 births.

Three studies had results that were mixed (Wagstaff \& Pradhan, 2005; Quimbo et al., 2011; Miller et al., 2013). Quimbo et al. (2011) find that insurance sites during the random trial ${ }^{5}$ experienced a 9 per cent reduction in the probability of wasting but no statistically significant difference between insured and uninsured in the rate of infection detected at hospital discharge. Miller et al. (2013) find no significant effect on the incidence of cough but a significant reduction in the number of days when children are not able to do their usual activities. Wagstaff and Pradhan (2005) find improvements in anthropometric outcomes among children under 5 but not among older children.

Finally, three other studies (Chen \& Jin, 2012; Fink et al., 2013; Guindon, 2014) do not find any significant effect on health outcomes (number of sickness or bed days and under-5 mortality, respectively).

\section{$V$ Discussion and Conclusions}

Despite a growing and large literature on the impact of health insurance in LMICs (Giedion \& Díaz, 2010; Spaan et al., 2012), we find only 13 studies for seven countries that assess the impact of health insurance on children. Nine out of 10 studies reviewed in this paper provide consistent evidence that health insurance provides financial protection. The results are more mixed when it comes to health-care utilisation and health outcomes: a positive effect was found in six out of 10 studies for health-care utilisation and in four out of 10 studies for health outcomes. For health-care

\footnotetext{
${ }^{5}$ The trial was conducted in the late 1990s and early 2000s.
}

utilisation, the other four studies offer mixed results.

A number of interesting discussion points emerge from this review. The general synthesis of results for the 13 studies is that insurance helps with financial protection while providing mixed impact on utilisation and health outcomes for children. This stands in contrast to results of other reviews. For instance, Giedion et al. (2013), considering broadly universal health care, finds that insurance tends to increase levels of utilisation across all services but has little to no impact on financial protection. For the informal sector, Acharya et al. (2013) find no evidence that health insurance in the informal sector impacts utilisation, financial protection and health outcomes.

The mixed results in this review regarding overall utilisation may be explained by the fact that children under insurance tend to use primary and preventative services at a higher rate than inpatient services. Two studies in Vietnam found a larger impact of health insurance on the use of outpatient relative to inpatient care for children under the age of 6 (Nguyen et al., 2012; Palmer et al., 2015). This finding is consistent with the RAND experiment where co-payments did not affect the probability of an inpatient visit of children (Manning et al., 1987). Improved access to primary and preventative care such as immunisations through outpatient contacts may have led to a reduction in the probability of hospitalisation for insured younger children. These services are also typically better covered than inpatient services under insurance, which may explain negative impacts on the financial burden of accessing care.

Several studies cover the same programs in Vietnam. Two studies cover the Voluntary Health Insurance program and its impact on school-age children and have consistent results overall, although the data come from the 1990s for Wagstaff and Pradhan (2005) and from the 2000s for Guindon (2014). In addition, three studies assess Vietnam's health insurance program for children under age 6 using the same data but different methods. They return findings that are somewhat different on health-care utilisation and financial protection. For instance, Palmer et al. (2015) find a significant increase in both outpatient and inpatient utilisation, while Guindon (2014) finds a significant effect only for outpatient visits, and Nguyen and Wang (2013) do not. 
To the extent that different methods address endogeneity in differing degrees, concerns of self-selection and unobserved heterogeneity may be a significant issue, at least in the case of health insurance for young children in Vietnam. Furthermore, the estimation of different treatment effects - local average treatment effect for regression discontinuity (Palmer et al., 2015) versus average treatment effect for the difference-in-difference estimation strategy for the other two papers - may have contributed to the different findings. These different results for Vietnam's programs contrast with those from a review of the literature in the United States where studies with different methods lead to similar results (Buchmueller et al., 2005).

This review is not without limitations, and thus gives rise to opportunities for further research. The greatest limitation relates to the small number of robust studies on the topic. More research is needed that evaluates the impact of health insurance programs on children in LMICs, as many countries are adopting or are considering adopting health insurance programs, or are broadly moving towards universal health care. The findings of the review are of course constrained by the limitations of the studies in the literature. Many studies on the impact of universal health insurance programs in LMICs do not present separate results for children and thus did not meet the search criteria of this review (e.g. Jowett et al., 2003; Axelson et al., 2009; Wagstaff, 2010; Nguyen, 2011). This represents a missed opportunity to understand the healthseeking behaviours and health outcomes of this important subpopulation. More research is needed that evaluates the impact of health insurance programs targeted at children, and studies that assess the impact of insurance programs for all ages need to separate out effects on children.

In addition, in the seven studies on health insurance programs for all ages included in this review, a comparison of results on utilisation and health outcomes for adults and children is done in only three studies (Chen \& Jin, 2012; Fink et al., 2013; Lu et al., 2012). In three studies, the comparison is not possible because different utilisation or health outcome indicators are used for children (e.g. immunisations completed). When generic indicators are used (e.g. number of inpatient or outpatient visits), studies should, when possible, break down results for adults and children due to potentially different health-careseeking behaviours as well as the inherent importance of child health to human development.

Future studies also need to document and identify the effects of specific characteristics of health insurance programs (e.g. benefits, copayments) and of supply-side factors. Threequarters of the papers under review are focused on Asian countries so there exists a geographical limitation, with only few impact evaluations for Africa and Latin America. In addition, only three studies reviewed in this paper evaluated impacts on subgroups of children. More nuanced research is needed on how health insurance affects children from ethnic minorities, children with disabilities, children with chronic health conditions and poor children.

Only three of the studies in the review analyse the supply-side aspects of the health insurance program or of a broader health-care reform (Wagstaff \& Yu, 2007; Giedion \& Uribe, 2009; Gruber et al., 2014), and three more studies mention in the discussion how supply-side factors could be affecting their results (Chen \& Jin, 2012; Fink et al., 2013; Palmer et al., 2015). Results suggest that supply-side considerations are important factors influencing the consequences of health insurance reforms on children. For instance, Gruber et al. (2014) find that increased funding of hospitals for the poor, and reduced copayments, increased health-care utilisation, especially among the poor and reduced infant mortality in poorer provinces in Thailand. More attention needs to be paid to the supply-side factors and how they may influence results of health insurance programs.

Finally, the outcomes covered in the studies reviewed in this paper are limited by the data under study. They tend to be short-term outcomes and come from general household survey data that are collected for purposes other than studying health care and health insurance. They often lack details on insurance plans, health-care services and health status. For instance, regarding inpatient care, we found several studies that examine the effects of insurance on any hospital utilisation by children. However, these studies do not differentiate between avoidable and unavoidable inpatient care, as has sometimes been done in the literature in high-income countries (Buchmueller et al., 2005). Some of the mixed results on the impact of health insurance on care utilisation and health outcomes are perhaps due to the limited information available in standard household surveys. For instance, measures of any contact with a 
health provider in the past year are crude measures of health-care utilisation, and these may explain the Wagstaff and Pradhan (2005) finding that availability of health care has no effect for children under 5. Mortality used in some studies may be too crude a measure of health to capture health improvements that may result from health insurance and may explain why Chen and Jin (2012) and Fink et al. (2013) find no effect on under-5 mortality.

Further research is needed that enhances the study of service utilisation, financial protection, and health outcomes among children under insurance in LMICs. Service utilisation indicators should be directly related to the benefits expected for the health insurance program under study. Health outcome indicators should be directly related to the health-care services that are expected to be affected by health insurance and that are likely to lead to health improvements (e.g. immunisation). Non-health outcome indicators should also be considered: only one of the studies in this review covered a non-health outcome: Chen and Jin (2012) considering school enrolment.

\section{REFERENCES}

Acharya, A., Vellakkal, S., Taylor, F., Masset, E., Satija, A., Burke, M. and Ebrahim, S. (2013), 'The Impact of Health Insurance Schemes for the Informal Sector in Low- and Middle-Income Countries: A Systematic Review', World Bank Policy Research Working Paper WPS 6324, World Bank, Washington, DC.

Axelson, H., Bales, S., Minh, P.D., Ekman, B. and Gerdtham, U.-G. (2009), 'Health Financing for the Poor Produces Promising Short-Term Effects on Utilization and Out-of-Pocket Expenditure: Evidence from Vietnam', International Journal for Equity in Health, 8, 20.

Behrman, J. and Rosenzweig, M.R. (2004), 'The Returns to Increasing Body Weight', Review of Economics and Statistics, 86, 586-601.

Brenner, S., Muula, A.S., Robyn, P.J., Barnighausen, T., Sarker, M., Mathanga, D.P. and De Allegri, M. (2014), 'Design of an Impact Evaluation Using a Mixed Methods Model - An Explanatory Assessment of the Effects of Results-Based Financing Mechanisms on Maternal Healthcare Services in Malawi', BMC Health Services Research, 14, 180.

Buchmueller, T.C., Grumbach, K., Kronick, R. and Kahn, J.G. (2005), 'The Effect of Health Insurance on Medical Care Utilization and Implications for Insurance Expansion: A Review of the Literature', Medical Care Research and Review, 62, 3-30.
Camacho, A. and Conover, E. (2013), 'Effects of Subsidized Health Insurance on Newborn Health in a Developing Country', Economic Development \& Cultural Change, 61, 633-58.

Chen, Y. and Jin, G.Z. (2012), 'Does Health Insurance Coverage Lead to Better Health and Educational Outcomes? Evidence from Rural China', Journal of Health Economics, 31 (1), 1-14.

Ching, P. (1995), 'User Fees, Demand for Children's Health Care and Access across Income Groups: The Philippine Case', Social Science and Medicine, 41, 37-46.

Fink, G., Robyn, P.J., Sie, A. and Sauerborn, R. (2013), 'Does Health Insurance Improve Health? Evidence from a Randomized Community-Based Insurance Rollout in Rural Burkina Faso', Journal of Health Economics, 32, 1043-56.

Giedion, U. and Díaz, Y. (2010), 'A Review of the Evidence', in Escobar, M.-L., Griffin, C.C., Shaw, R.P. (eds), The Impact of Health Insurance in Lowand Middle-Income Countries. Brookings Institution, Washington, DC; 13-32.

Giedion, U. and Uribe, M.V. (2009), 'Colombia's Universal Health Insurance System', Health Affairs, 28, 853-63.

Giedion, U., Alfonso, E.A. and Díaz, Y. (2013), 'The Impact of Universal Coverage Schemes in the Developing World: A Review of the Existing Evidence', Universal Health Coverage (UNICO) Studies Series No. 25, World Bank, Washington, DC.

Gruber, J., Hendren, N. and Townsend, R.M. (2014), 'The Great Equalizer: Health Care Access and Infant Mortality in Thailand', American Economic Journal: Applied Economics, 6 (1), 91-107.

Guindon, G.E. (2014), 'The Impact of Health Insurance on Health Services Utilization and Health Outcomes in Vietnam', Health Economics, Policy \& Law, 9, 359-82.

Jowett, M., Contoyannis, P. and Vinh, N.D. (2003), 'The Impact of Public Voluntary Health Insurance on Private Health Expenditures in Vietnam', Social Science and Medicine, 56, 333-42.

Khandker, S.R., Koolwal, G.B. and Samad, H.A. (2010), Handbook on Impact Evaluation: Quantitative Methods and Practices. World Bank, Washington, DC.

Kraft, A., Quimbo, S., Solon, O., Shimkhada, R., Florentino, J. and Peabody, J. (2009), 'The Health and Cost Impact of Care Delay and the Experimental Impact of Insurance on Reducing Delays', Journal of Pediatrics, 155, 281-5.

La Forgia, G. and Nagpal, S. (2012), Government Sponsored Health Insurance in India: Are You Covered?. World Bank, Washington, DC. Available from: http://documents.worldbank.org/curated/en/64 4241468042840697/Government-sponsored-healthinsurance-in-India-are-you-covered.

Lagomarsino, G., Garabrant, A., Adyas, A., Muga, R. and Otoo, N. (2012), 'Moving towards Universal Health Coverage: Health Insurance Reforms in Nine 
Developing Countries in Africa and Asia', Lancet, 380 (9845), 933-43.

Leibowitz, A., Manning, W., Keeler, E.B., Duan, N., Lohr, K.N. and Newhouse, J.P. (1985), 'The Effect of Cost Sharing on the Use of Medical Services of Children: Interim Results from a Randomized Controlled Trial', Pediatrics, 75, 942-51.

Lu, C., Chin, B., Lewandowski, J.L., Basinga, P., Hirschhorn, L.R., Hill, K., Murray, M. and Binagwaho, A. (2012), 'Towards Universal Health Coverage: An Evaluation of Rwanda Mutuelles in Its First Eight Years', PLoS ONE, 7 (6), e39282.

Manning, W.G., Newhouse, J.P., Duan, N., Keeler, E.B. and Leibowitz, A. (1987), 'Health Insurance and the Demand for Medical Care: Evidence from a Randomized Experiment', American Economic Review, 77 (3), 251-77.

Miller, G., Pinto, D. and Vera-Hernandez, M. (2013), 'Risk Protection, Service Use, and Health Outcomes under Colombia's Health Insurance Program for the Poor', American Economic Journal: Applied Economics, 5 (4), 61-91.

Nguyen, C.V. (2011), 'The Impact of Voluntary Health Insurance on Health Care Utilization and Out of Pocket Payments: New Evidence for Vietnam', Health Economics, 21, 946-66.

Nguyen, H. and Wang, W. (2013), 'The Effects of Free Government Health Insurance among Small Children - Evidence from the Free Care for Children Under Six Policy in Vietnam', International Journal of Health Planning and Management, 28, 3-15.

Nguyen, K., Khuat, O., Ma, S., Pham, D., Khuat, G. and Ruger, J. (2012), 'Impact of Health Insurance on Health Care Treatment and Cost in Vietnam: A Health Capability Approach to Financial Protection', American Journal of Public Health, 102, 1450-61.

Palmer, M., Mitra, S., Mont, D. and Groce, N. (2015), 'The Impact of Health Insurance for Children under Age 6: A Regression Discontinuity Approach', Social Science and Medicine, 145, 217-26.

Phelps, C. (1997), Health Economics, 2nd edn. Addison-Wesley, Reading, MA.

Quimbo, S., Peabody, J., Shimkhada, R., Florentino, J. and Solon, O. (2011), 'Evidence of a Causal Link between Health Outcomes, Insurance Coverage, and a Policy to Expand Access: Experimental Data from Children in the Philippines', Health Economics, 20, 620-30.

Sauerborn, R., Nougtara, A. and Latimer, E. (1994), 'The Elasticity of Demand for Health Care in Burkina Faso: Differences across Age and Income Groups', Health Policy and Planning, 9 (2), 185-92.
Sepulveda, J. and Murray, C. (2014), 'The State of Global Health in 2014', Science, 345 (6202), 1275-8.

Spaan, E., Mathijssen, J., Tromp, N., McBain, F., ten Have, A. and Baltussen, R. (2012), 'The Impact of Health Insurance in Africa and Asia: A Systematic Review', Bulletin of the World Health Organization, 90, 685-92.

Svoronos, T., Macauley, E.J. and Kruk, M.E. (2014), 'Can the Health System Deliver? Determinants of Rural Liberians' Confidence in Health Care', Health Policy and Planning, 30, 823-9.

United Nations (2015), 'World Population Prospects: The 2015 Revision, Key Findings and Advance Tables', Working Paper No. ESA/P/WP.241, Department of Economic and Social Affairs, Population Division, UN, New York. Available from: https:// esa.un.org/unpd/wpp/Publications/Files/Key_Findin gs_WPP_2015.pdf.

United Nations Development Programme (2016), 'Sustainable Development Goals', UNDP. Available from: http://www.undp.org/content/undp/en/home/su stainable-development-goals.html.

Wagstaff, A. (2010), 'Estimating Health Insurance Impacts under Unobserved Heterogeneity: The Case of Vietnam's Health Care Fund for the Poor', Health Economics, 19, 189-208.

Wagstaff, A. and Pradhan, M. (2005), 'Health Insurance Impacts on Health and Nonmedical Consumption in a Developing Country', World Bank Policy Research Working Paper WPS 3563, World Bank, Washington, DC.

Wagstaff, A. and Yu, S. (2007), 'Do Health Sector Reforms Have Their Intended Impacts? The World Bank's Health VIII Project in Gansu Province, China', Journal of Health Economics, 26, 505-35.

Wang, H., Liddell, C.A., Coates, M.M., et al. (2014), 'Global, Regional, and National Levels of Neonatal, Infant, and Under-5 Mortality during 1990-2013: A Systematic Analysis for the Global Burden of Disease', Lancet, 6736 (14), 60497-9.

WHO (2010) Health Systems Financing: The Path to Universal Coverage. World Health Report 2010. World Health Organization, Geneva.

WHO (2014), Universal Health Coverage: Supporting Country Needs. World Health Organization, Geneva.

Yip, W. and Berman, P. (2001), 'Targeted Health Insurance in a Low Income Country and Its Impact on Access and Equity in Access: Egypt's School Health Insurance', Health Economics, 10, 207-20. 


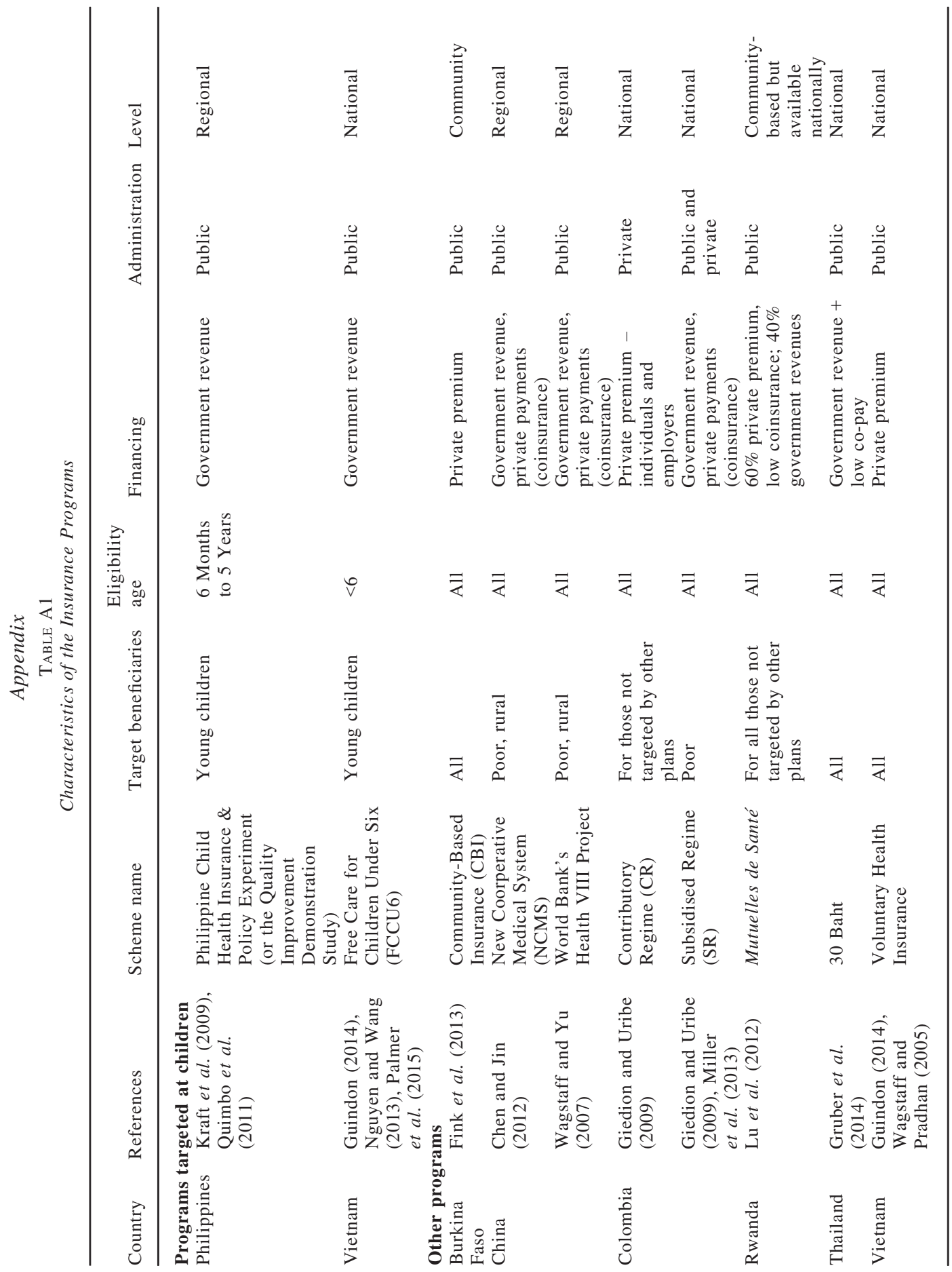

